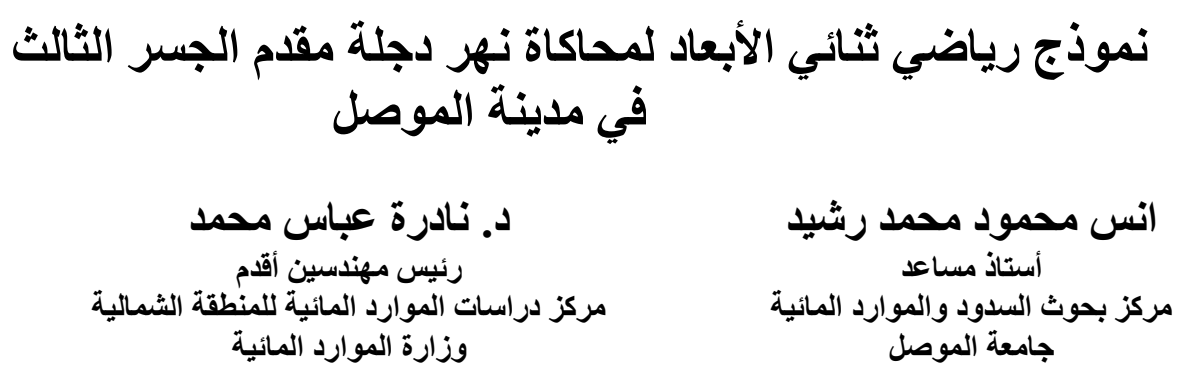

\title{
الخلاصة
}

يتناول البحث تحليل هيدروديناميكي لامتداد نهر دجلة مقدم الجسر الثالث في مدينة الموصل والثة والذي يمتاز بوجود

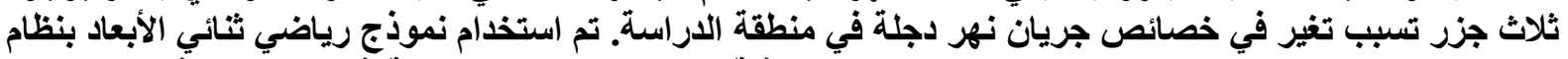

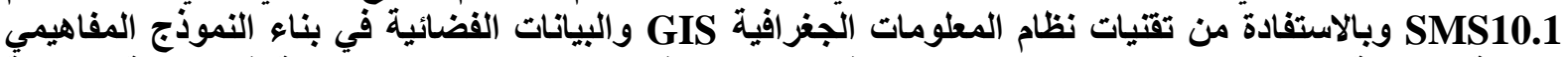

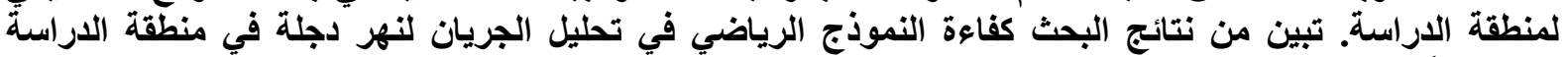

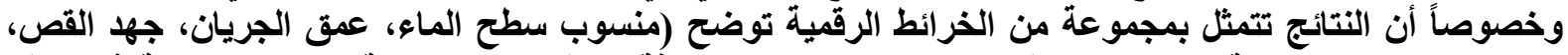
اتجاهات الجريان، سرعة الجريان، مواقع النحر والترسيب) بالإضافة للتوقعات المستقبلية لشكل نهر دجلة في موقع التريان

الكلمات الدالة: نهر دجلة، محاكاة، نقل الرسوبيات، تحليل الجريان، SMS.

\section{Two Dimensional Mathematical Models to Simulation Tigris River Upstream Third Bridge in Mosul City}

\author{
Anas M. M. Rasheed \\ Assistant professor \\ Dams and water resources research \\ center \\ University of Mosul
}

\author{
Dr. Nadira A. Mohammed \\ Senior chief engineer \\ Water resources studies center for \\ northern region project \\ Ministry of water resources
}

\begin{abstract}
:
The aim of this research is hydrodynamic analysis for Tigris river reach upstream the Third Bridge in Mosul city, and this reach have three islands changing the flow characteristics of Tigris river in the study area. Two dimensional mathematical model in SMS10.1 with geographical information system and satellite data are using to build the conceptual model for study area. The results showed that the efficiency of the mathematical model in analysis of Tigris river in the study area especially the results were presented by digital maps explain (water surface elevation, flow depth, shear stress, flow velocity, scour and deposition locations), in addition predications the shape of the Tigris river reach in the study area in the future.
\end{abstract}

Keywords: Tigris River, Simulation, Sediment transport, Flow analysis, SMS. 


\section{مقدمة:}

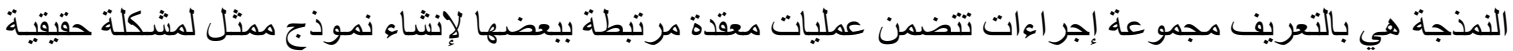

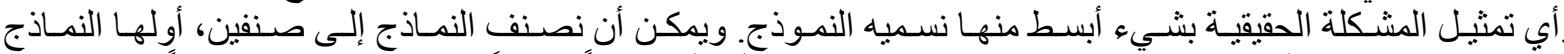

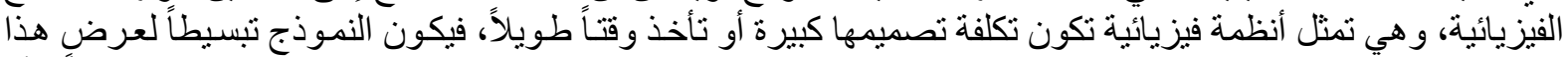

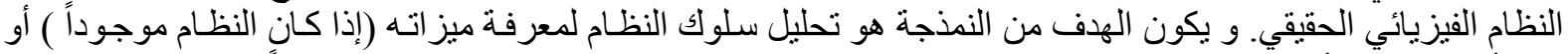

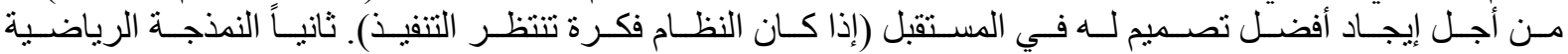

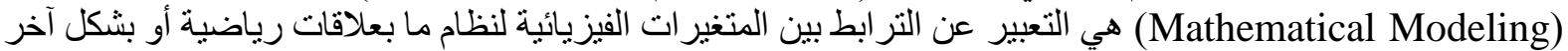

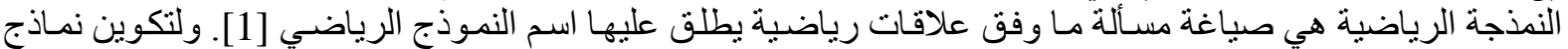

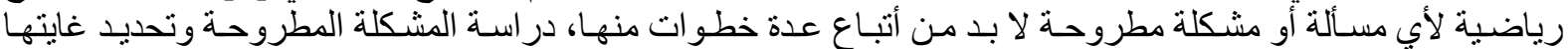

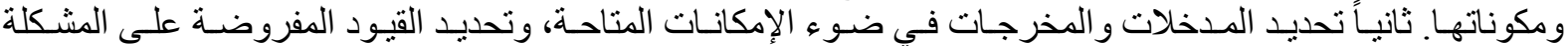
(Boundary conditions)

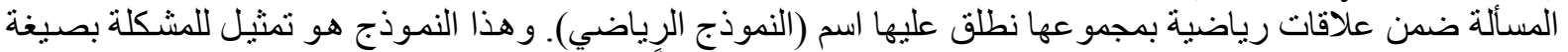

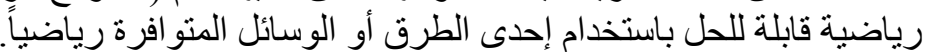

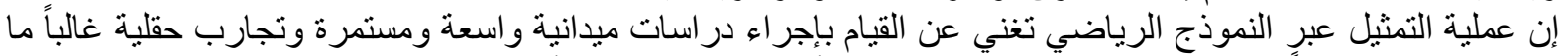

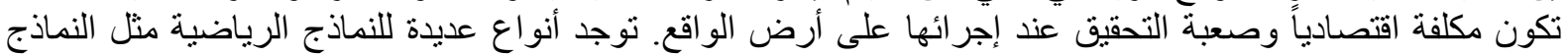

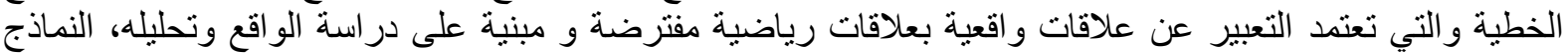
التصادفية (Stochastic models) و التي تعتمد المعادلات الإحصائية في بناء النموذجة. يعتبر النموذجة النمانية المفاهيمي

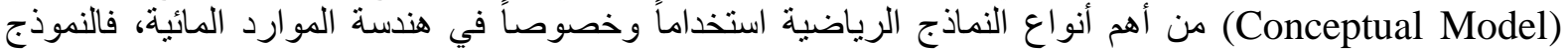

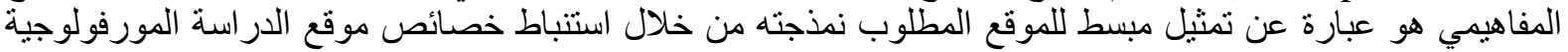

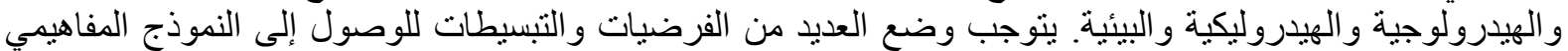

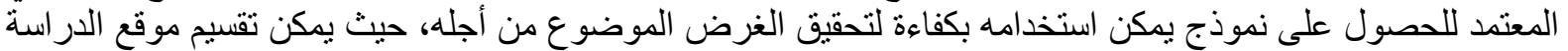

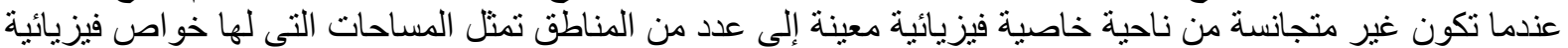

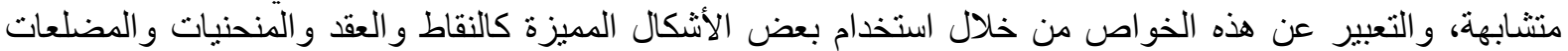

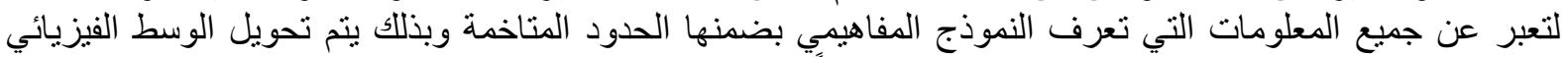

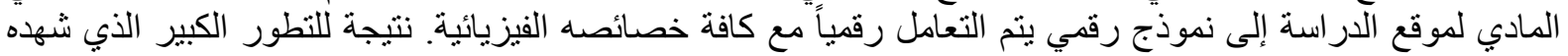

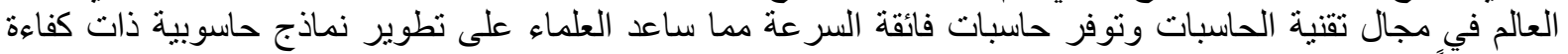

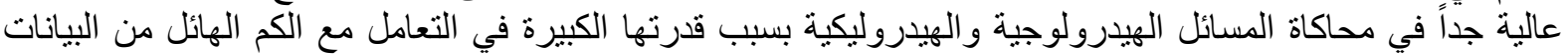

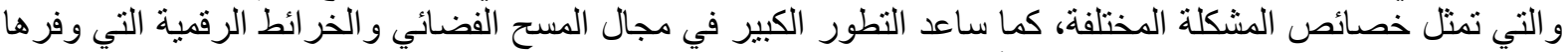

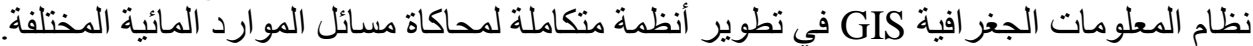

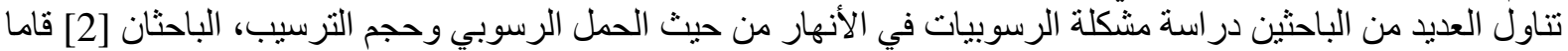

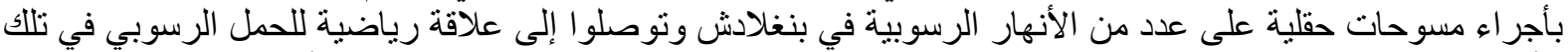

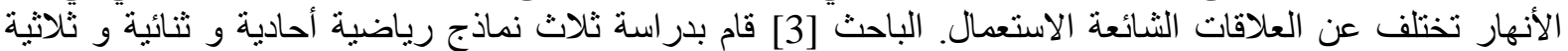

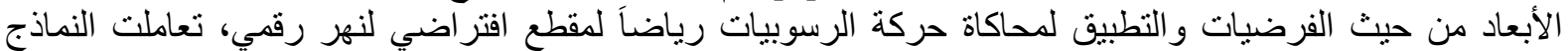

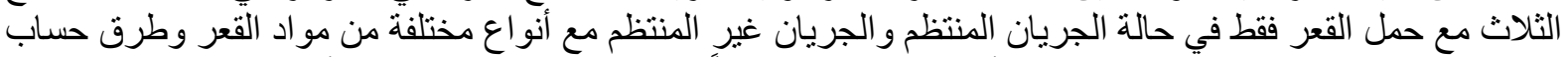

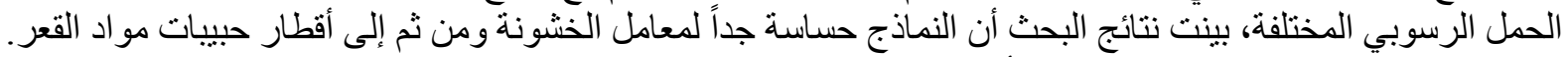

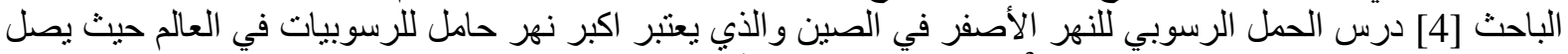

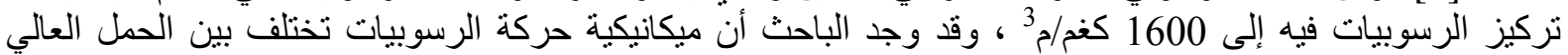
للرسوبيات وبين الحمل الطبيعي لها لذلك حلل كلا الحالتين وتوصل إلى صيغ رياضية جديدة خاصة بالنهر الأصفر في التي الني

الصين.

سيتم في البحث استنباط نموذج هيدروديناميكي لمحاكاة الخصائص الهيدروليكية وعملية النحر و الترسيب لمقطع نهر دجلة مقدم الجسر الثالث في مدينة الموصل باستخدام نظام نمذجة المياه السطحية (Surface Water Modeling System)

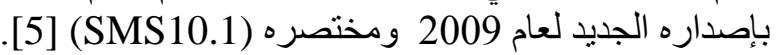

\section{النموذج الرياضي:}

يعتبر نظام نمذجة المياه السطحية (SMS) بيئة شاملة (أحادية ـ ثنائية ـ ثلاثية) الهيدروديناميكية باستخدام العناصر المحددة (Finite Elements) أو الفروقات المحددة (Finite differences) لنمذجة المياه السطحية والمنشات (RMA2, RAM4, TUFLOW 1D, TUFLOW 2D, CMS, الهيدروليكية باستخدام عدة نماذج رياضية الإنة FESWMS) الجريان المستقر (Steady state) أو الجريان غير المستقر (Unsteady state) بالإضافة إلى محاكاة حركة الملوثات 
و الملوحة ونقل الرسوبيات (النحر والترسيب)، ونشتيت طاقة الأمواج ودر اسة خصائص الأمواج (الاتجاهات و المقادير)

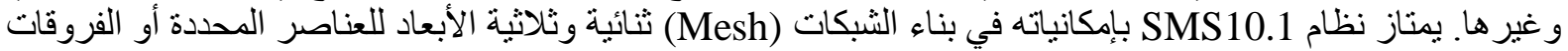

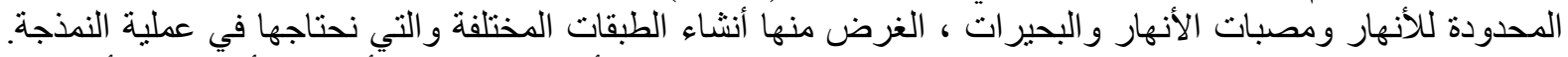

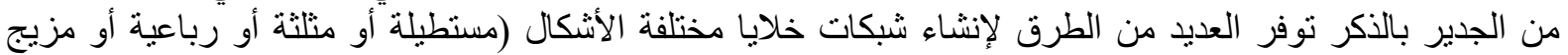

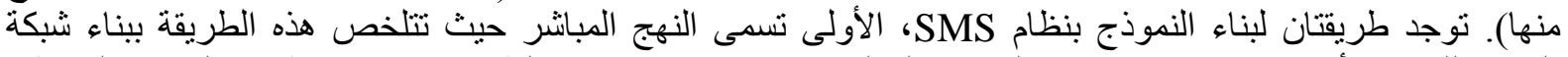

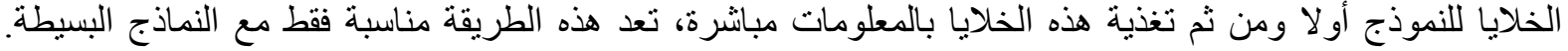

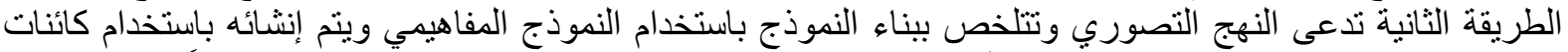

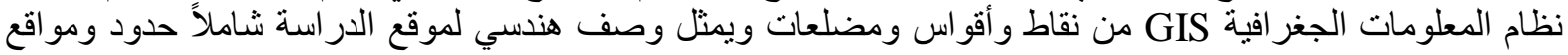
القتو ات وخصائص القعر و غير ها [6]، ومن ثم يتم تحويل النموذج المفاهيمي إلى شبكة الخلايا ليتم تغذيتها بالمدخلات عن التئ يستفيد نظام SMS10.1 من جميع إمكانيات نظم المعلومات المئات الجغرافية حيث يمتلك مجموعة كاملة من أدوات

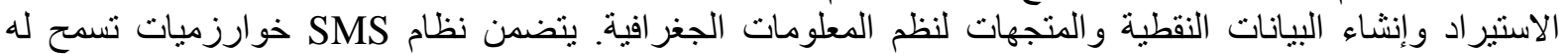

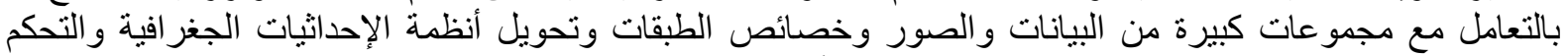

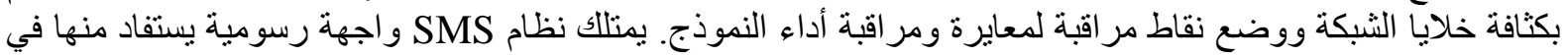

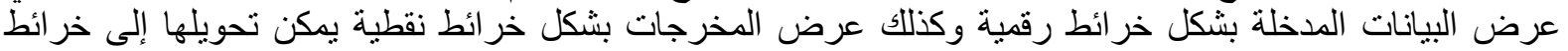
كنتورية ملونة ومضللة لقيم سر عة الجريان أو مناسيب القعر بعد حدوث عملية القية النحر و الترسيب. سيتم في البحث استخدام

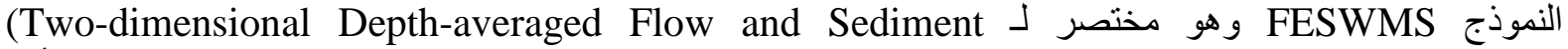
في محاكاة الخصائص الهيدروليكية للجريان و عملية النحر و الترسيب للرسوبيات وما ستؤول أليه

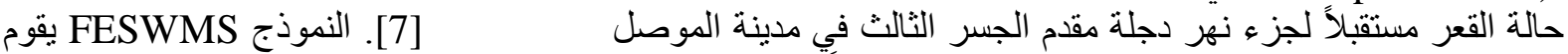

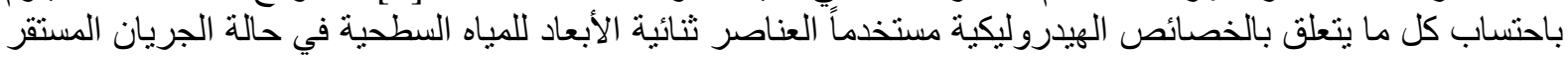

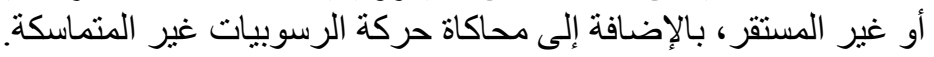

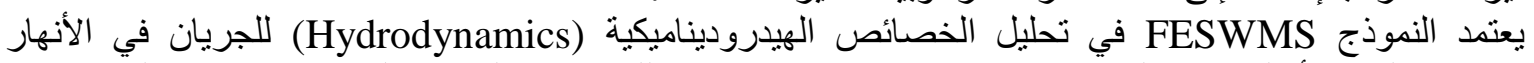

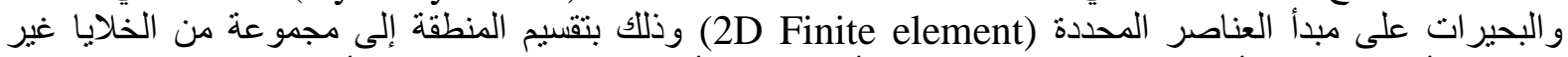

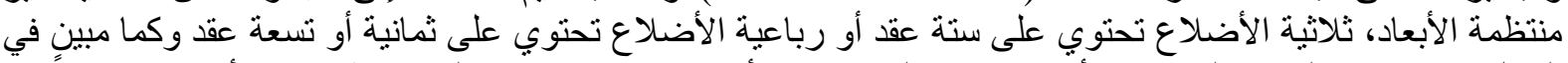

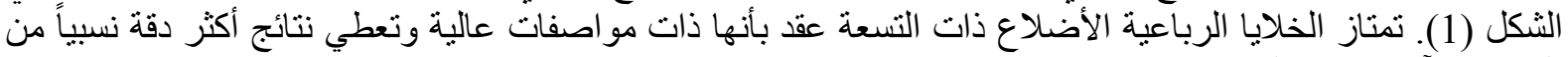
النو عين الآخرين من العقد.

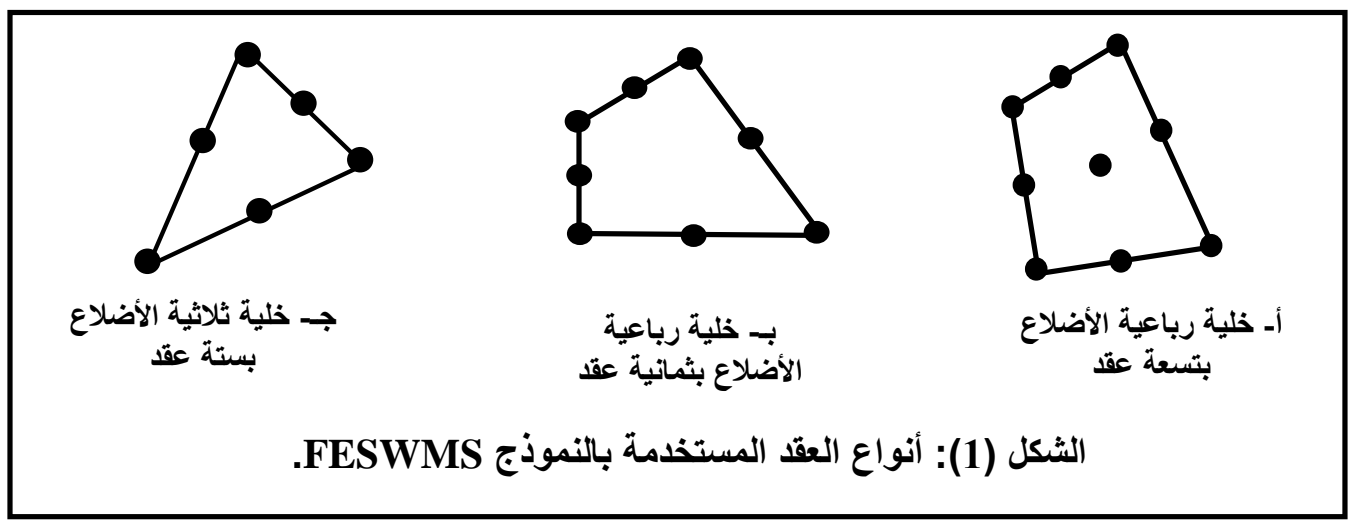

يعتبر نموذج FESWMS نموذج رياضي معقد نسبياً ولا يمكن أيجاز خلفيته الرياضية بشكل مختصر ولكن سيتم

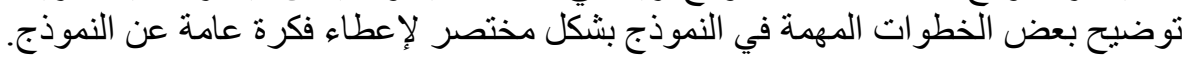

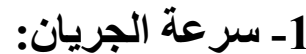

أن تحليل سرعة الجريان بالاتجاهين X و X بعتبر الجزء الأكثر أهمية في التحليل الهيدروديناميكي للجريان ويتم

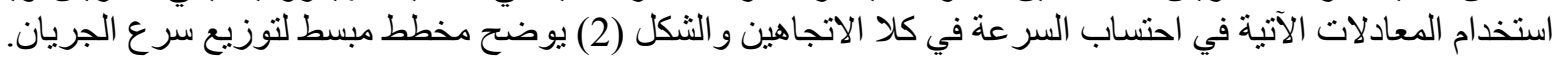

$$
U=\frac{1}{H} \int_{z_{b}}^{z_{w}} u d z
$$




$$
V=\frac{1}{H} \int_{z_{b}}^{z_{w}} v d z
$$

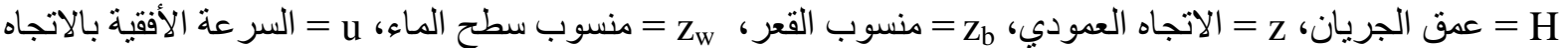

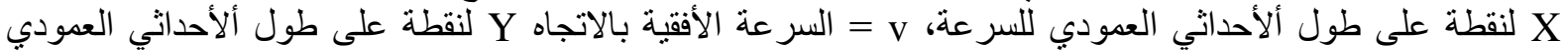

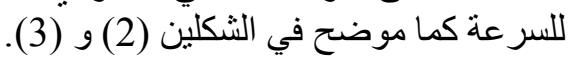

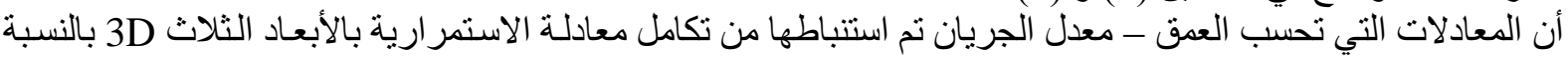

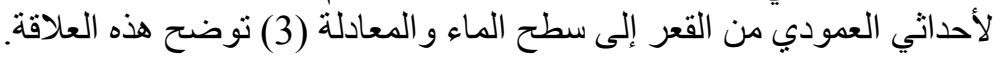

$\frac{\partial z_{w}}{\partial t}+\frac{\partial q_{1}}{\partial x}+\frac{\partial q_{2}}{\partial y}=q_{m}$

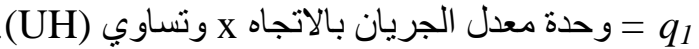

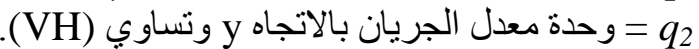

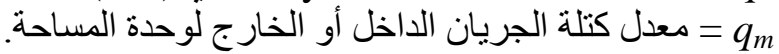

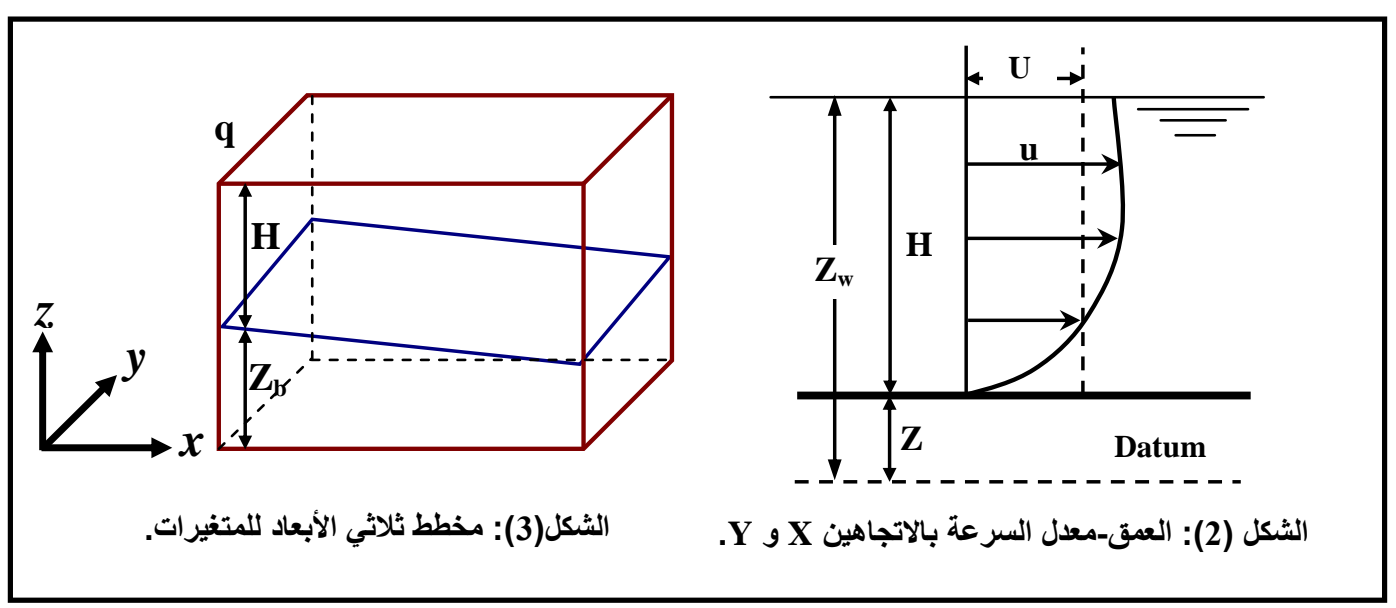

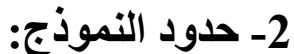

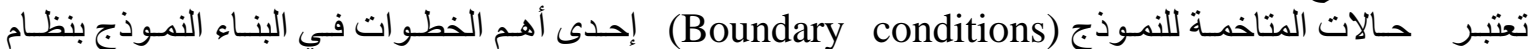

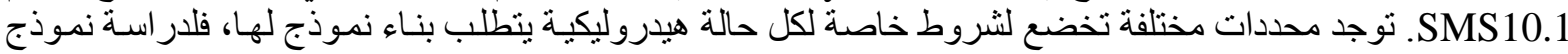

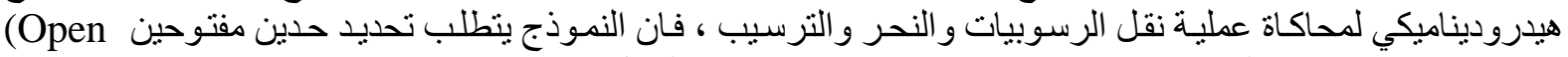
boundary)

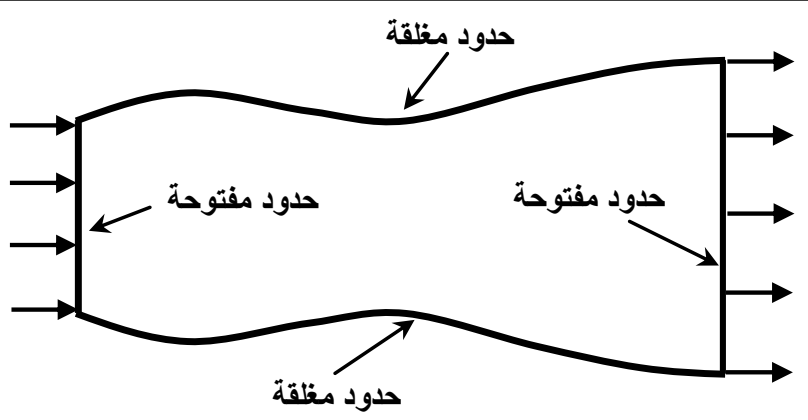

الثكل (4): يوضح بعض أنواع الحدود بنظام كنده 


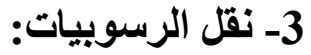

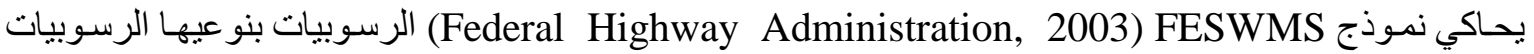

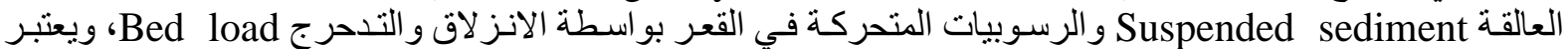
نموذج رياضي ثنائي الأبعاد في محاكاة عملية النحر و الترسيب. يستخدم النموذج معادلة الاستمر ارية للرسوبيات التربيات (المعادلة $\left(1-\eta_{s}\right) \frac{\partial z_{b}}{\partial t}+\frac{\partial q_{s 1}}{\partial x}+\frac{\partial q_{s 2}}{\partial y}=0$ 4) في حساب مناسيب القعر بعد عملية النحر و الترسيب.

حيث أن: $=$ = مسامية مو اد القعر ، و و و و

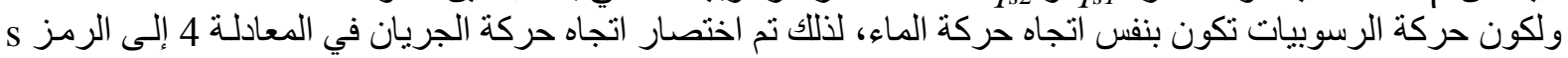
$\left(1-\eta_{s}\right) \frac{\partial z_{b}}{\partial t}+\frac{\partial q_{s}}{\partial s}=0$ لتصبح المعادلة بالشكل الاتي.

حيث أن: $q_{s}=\sum_{i} q_{s i}$ الرسوبيات المنكونة من أكثر من قطر من حبيبات مواد القعر.

$\left(1-\eta_{s}\right) \frac{\partial z_{b}}{\partial t}+\sum_{i} \frac{\partial q_{s}}{\partial s}=0$ لذلك تصبح المعادلة 4 بالشكل الاتي. $\frac{\partial\left(C_{s i} H\right)}{\partial t}+\frac{\partial\left(C_{s i} q_{1}\right)}{\partial x}+\frac{\partial\left(C_{s i} q_{2}\right)}{\partial y}=C_{s e}\left(C_{s i}^{*}-C_{s i}\right)$ تمثل المعادلة 8 معادلة نقل الرسوبيات في نموذج FESWMS. حيث أن:

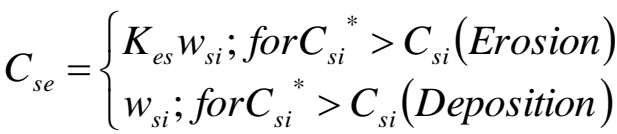
ويحتسب باستخدام المعادلة الآتية.

حيث أن:

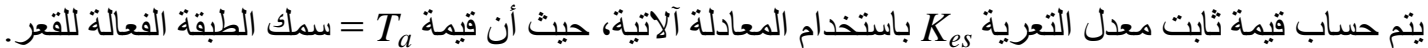
$K_{e s}=\frac{1}{\frac{T_{a}}{H}+\left(1-\frac{T_{a}}{H}\right) \exp \left[-1.5 \frac{w_{s i}}{u_{*}}\left(\frac{T_{a}}{H}\right)^{-1 / 6}\right]}$

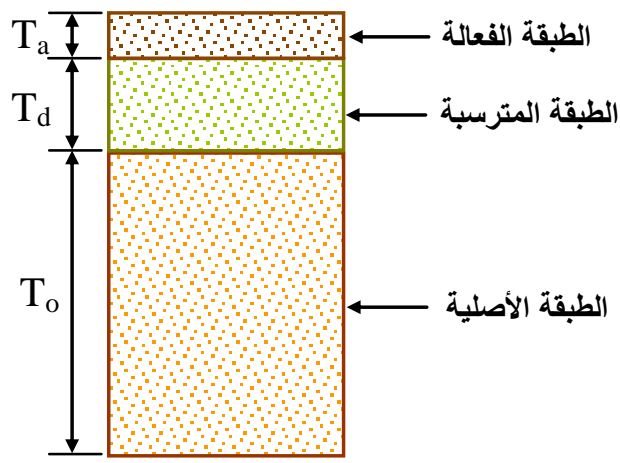

الشكل(5): مخطط يوضح طبقات القعر.

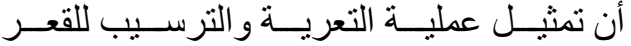

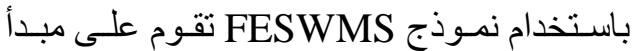

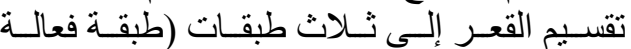
Deposition Active layer و layer و الثكل (5) يوضح مقطع للطبقات الثلاث للقعر.

تعتبر الطبقـة الفعالـة أهم طبقـة في النمـوذج وولا

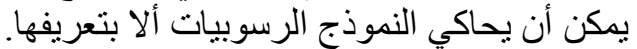

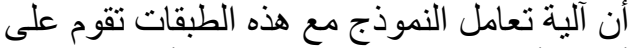

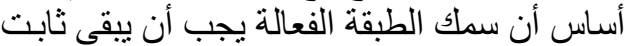

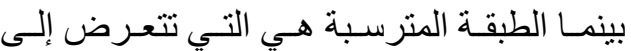

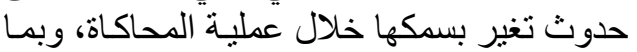




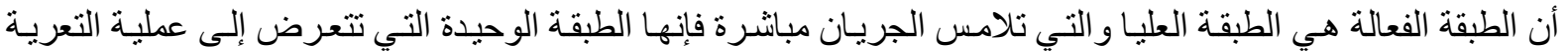

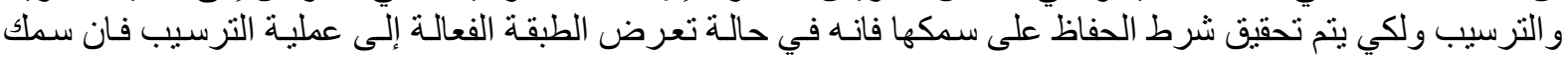

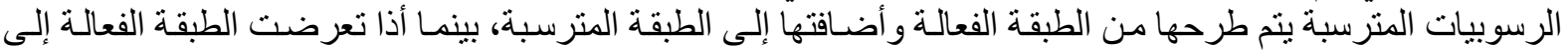
عملية تعرية فيتم إضافة سمك الرسوبيات المفقودة إلى الطبقة الفعالة وطرحها من الطبقة المنرسبة.

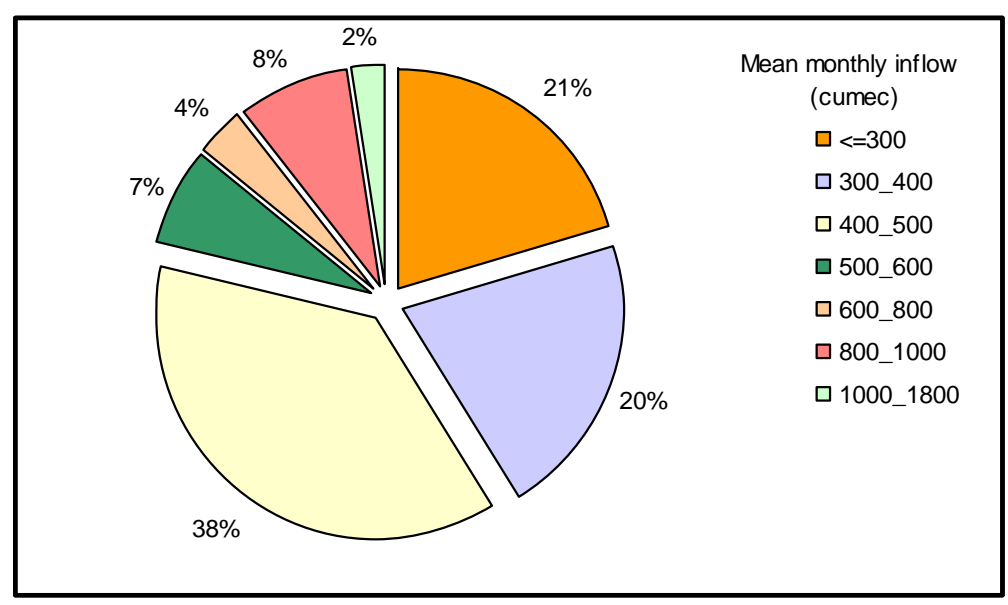

الثكل (6): التحليل الإحصائي لتصاريف نهر دجلة في مدينة الموصل.

التحليل الإحصائي لتصاريف نهر دجلة:

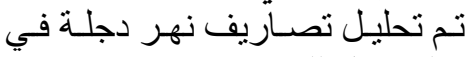
مدينة الموصل للفترة من سنة 1994 - 1906 -

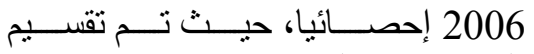

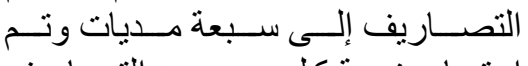
احتسـاب نسبة كل مدى من التصـاريف

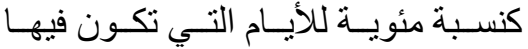

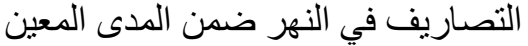

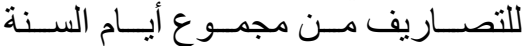
و الثكل (6) يوضح نتائج التحليل. حيث يلاحظ بـان مدى التصـاريف مـن

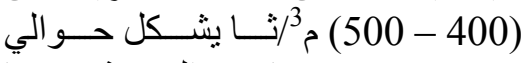

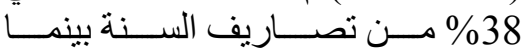
تصاريف الفيضـان العليا (800-1000)

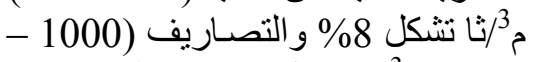
1800) مثا تشكل 2\% \% من التصاريف السنوية في نهر دجلة داخل مدينة الموصل.

موقع الدراسة:

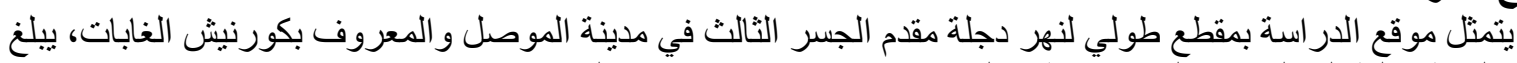

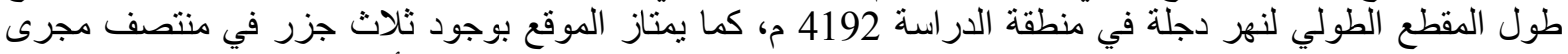

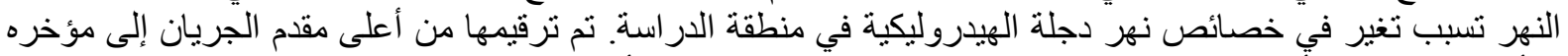

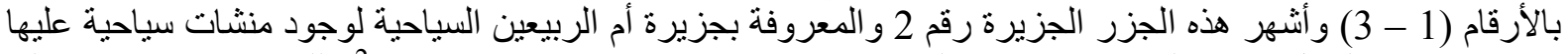

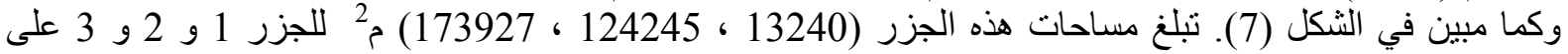
التو الي.

\section{خطوات بناء النموذج الرياضي لمنطقة الار اسة:}

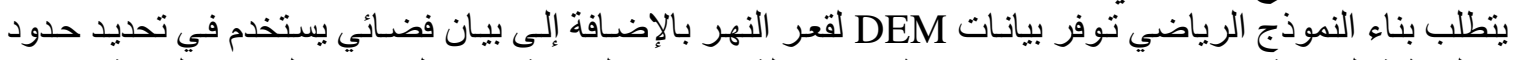

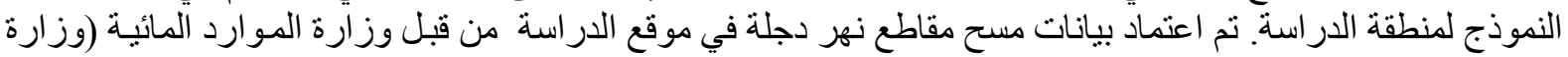

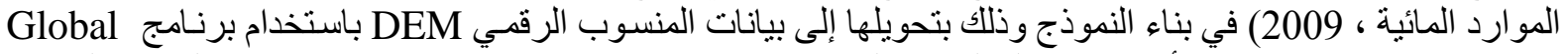

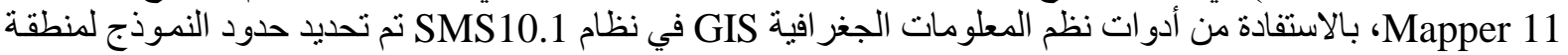

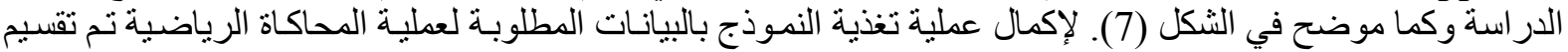

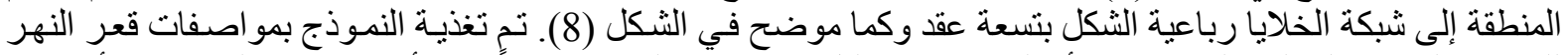

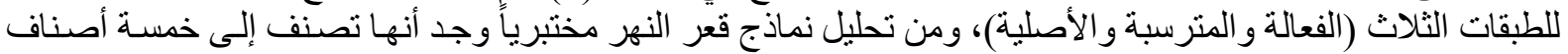

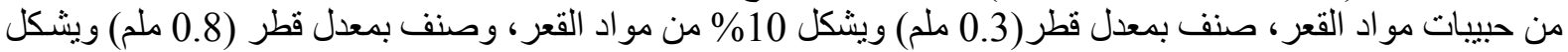

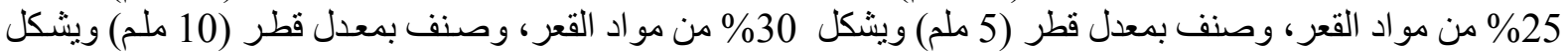

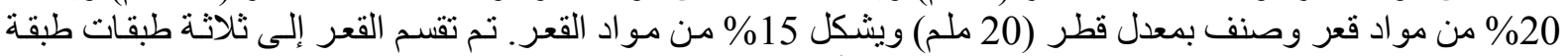
فعالة بسمك مو 20 سم وطبقة مترسبة بسمك 30 سم وطبقة أصلية بسمك 50 سم. 
رشيد : نموذج رياضي ثنائي الأبعاد لمحاكاة نهر دجلة مقدم الجسر الثالث في مدينة الموصل
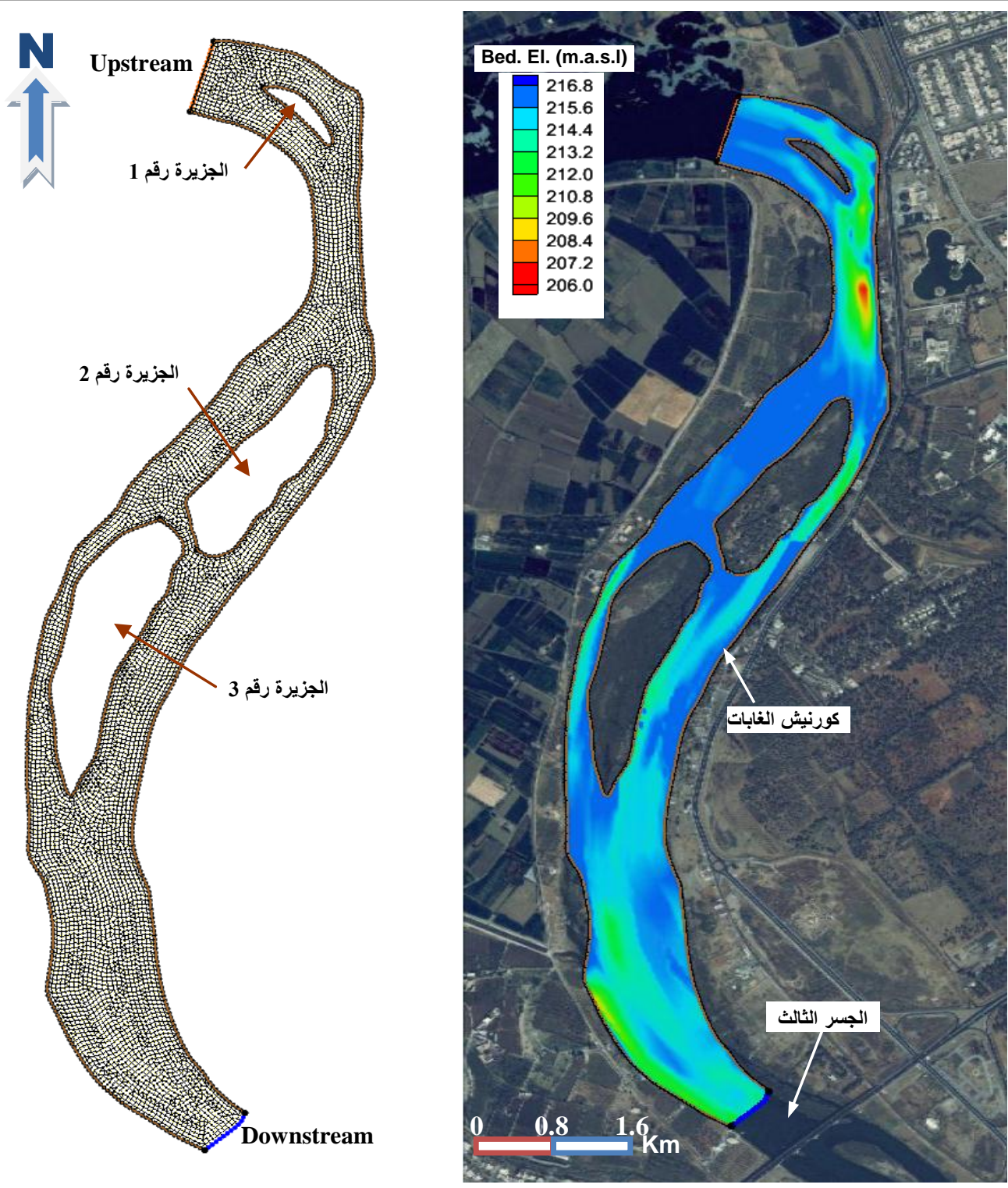

الثكل (8): شبكة الخلايا لمنطقة الدراسة.

الثكل (7): حدود منطقة الاراسة.

النتائج والمناقشة:

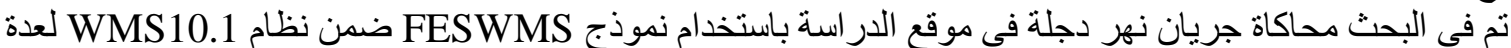

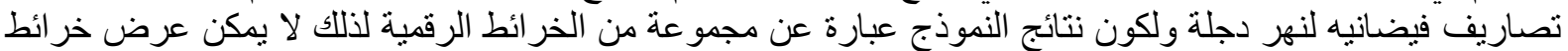

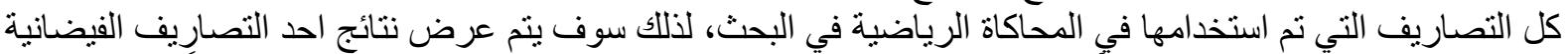

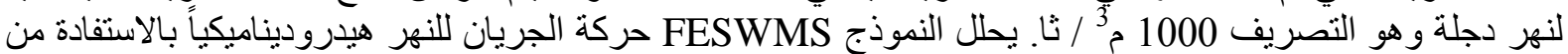

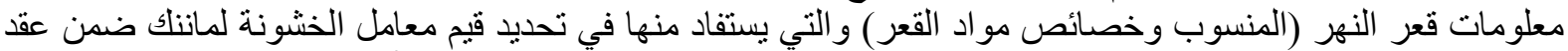

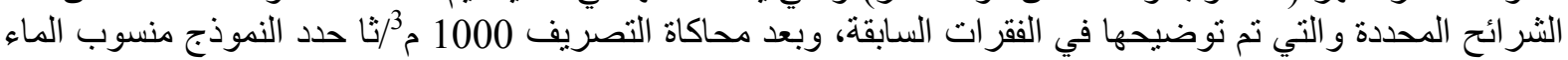

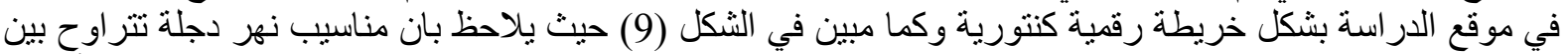

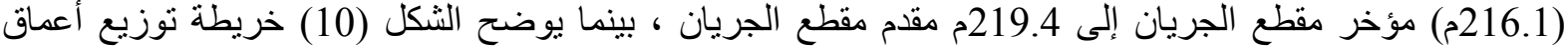

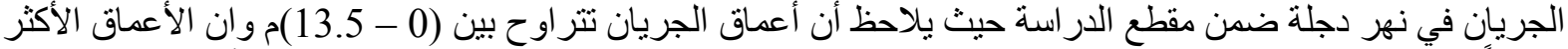

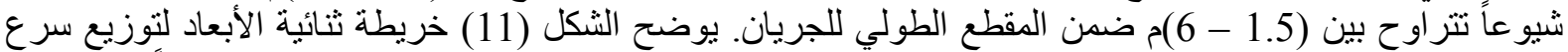

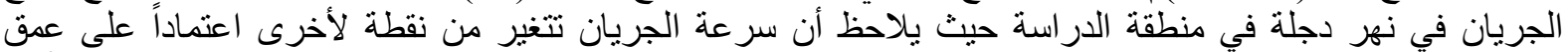

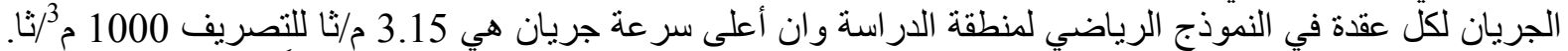
يمتاز نظام FESWMS بإمكانية تحليل ثنائي الأبعاد لاتجاهات الجريان الجيان في النهر هيدروديناميكياً بشكل خريطة رقمية 


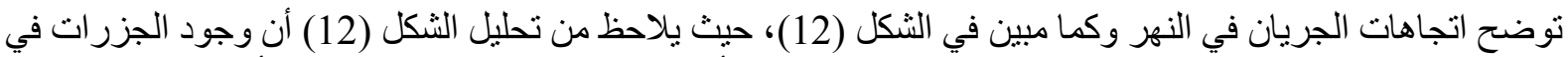

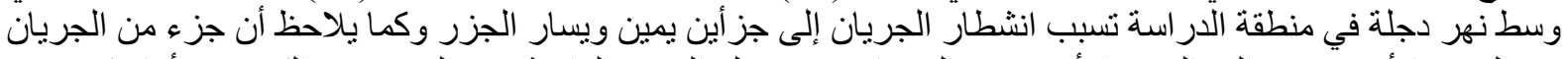

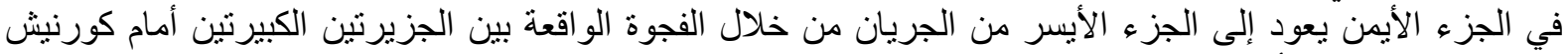

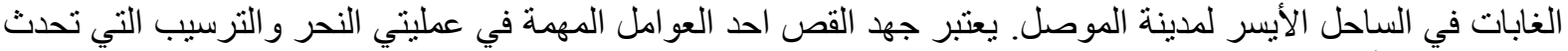

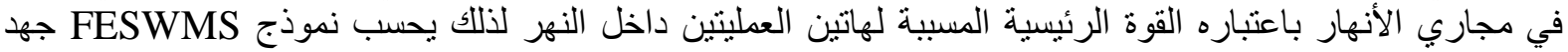

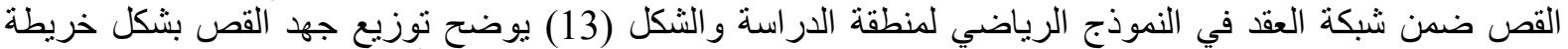

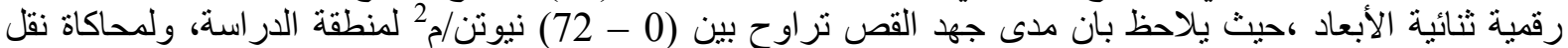

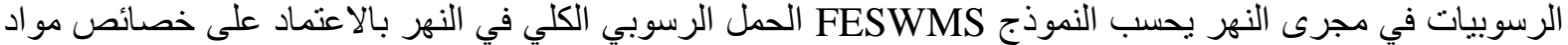
القعر و الجدول (1) يوضح الحمل الرسوبي الكلي للتصاريف التي تم محاكاتها في البحث.

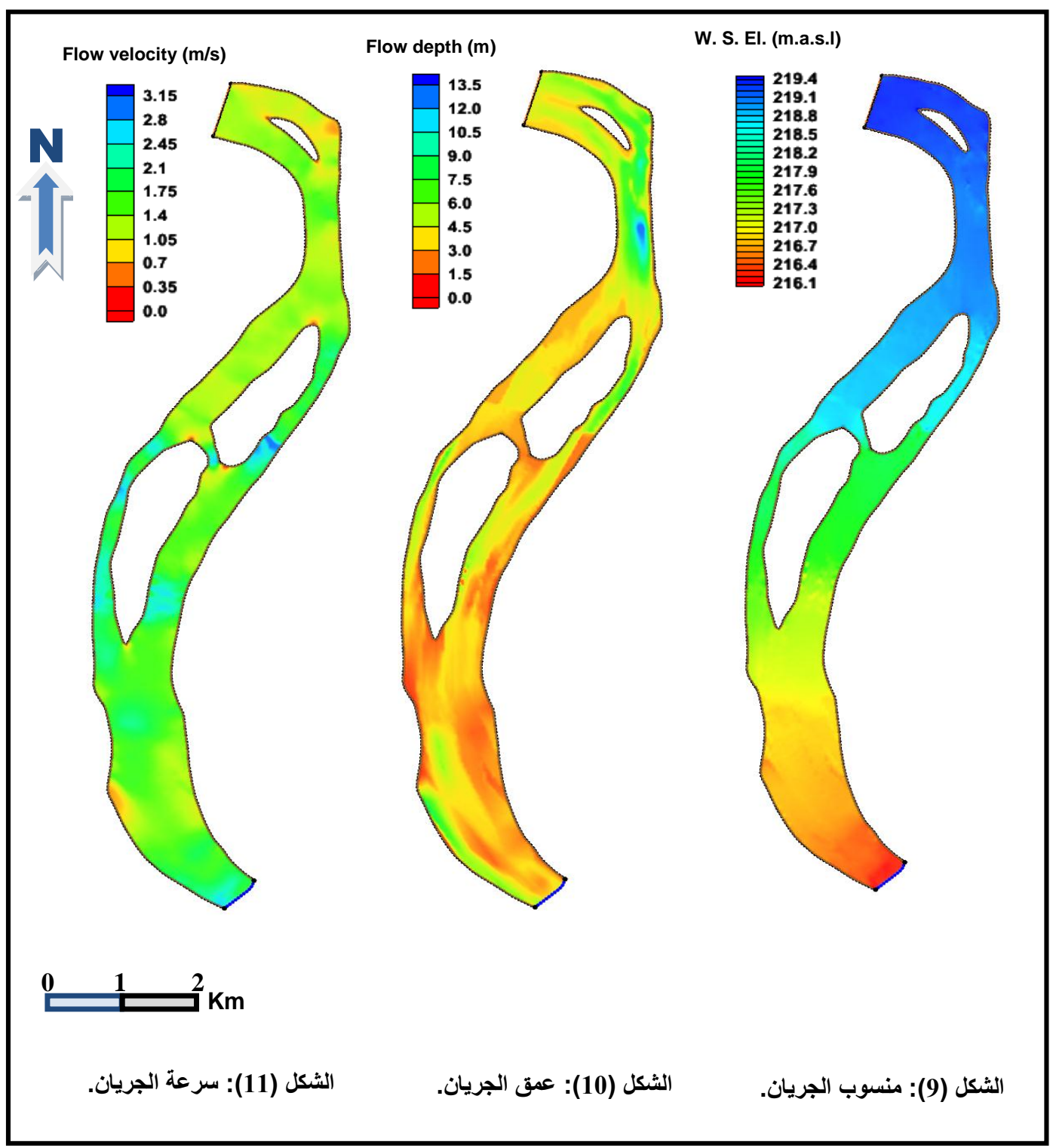

تم في البحث محاكاة حركة وتوزيع الرسوبيات في موقع الدر اسة والثكل (14) يوضح مو اقع النحر و الترسيب في

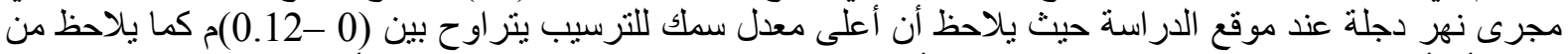

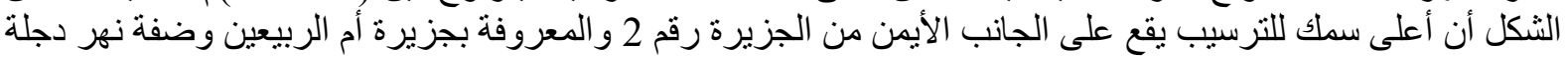

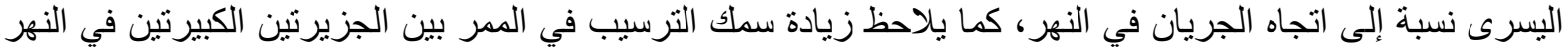

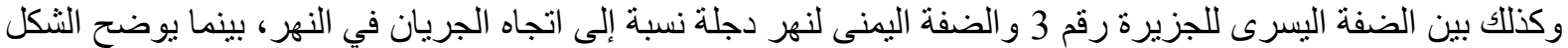

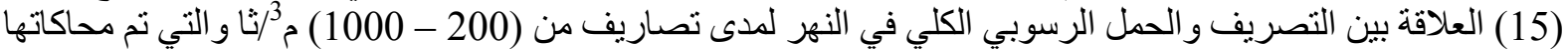
في البحث.وقد تبين من تحليل نوزيع الرسوبيات في مجرى نهر دجلة في منطقة الدراسة أن هنالك احتمالين لثكل نهر 


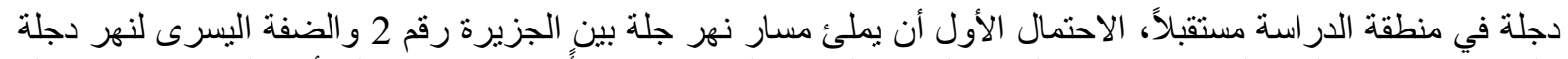

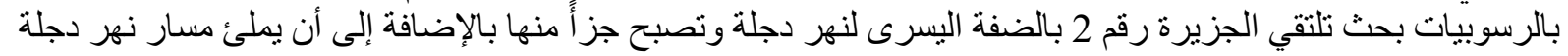

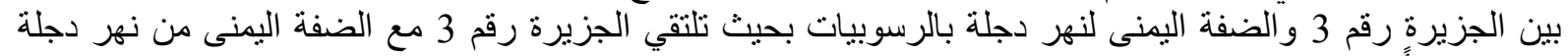

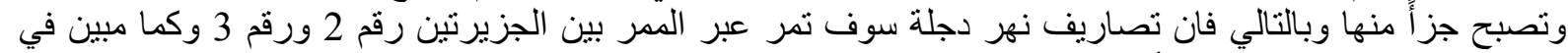

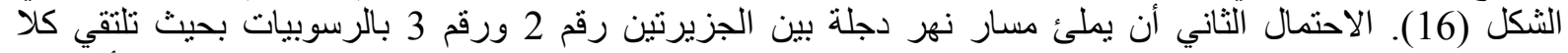

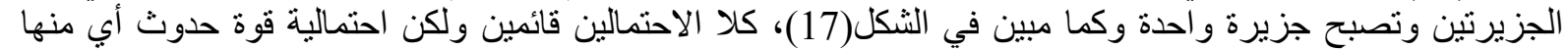
يعتمد على تذبذب التصاريف في نهر دجلة وتغير قوى النحر و الترسيب في مجرى النهر في منطقة الدراسة.

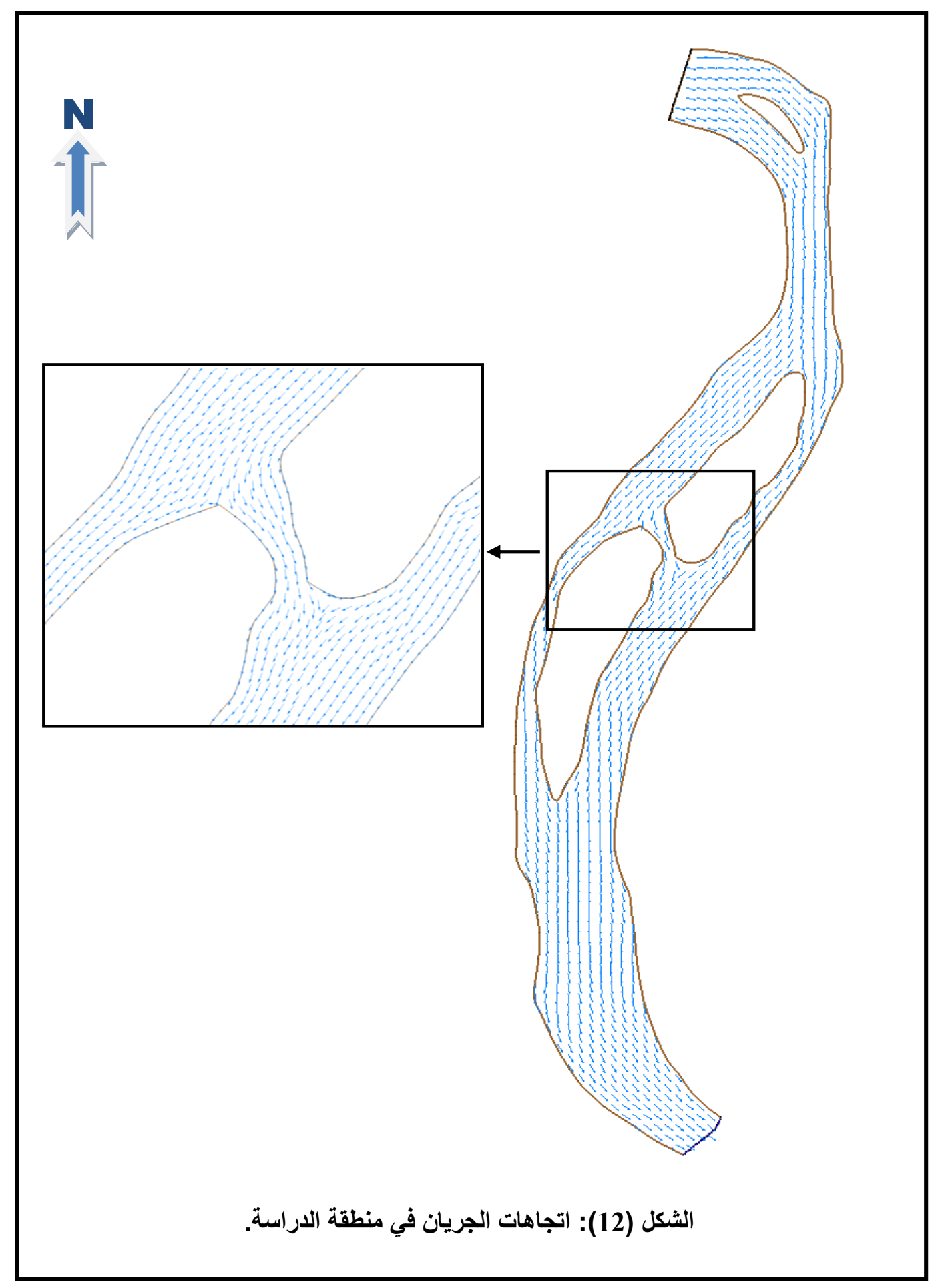




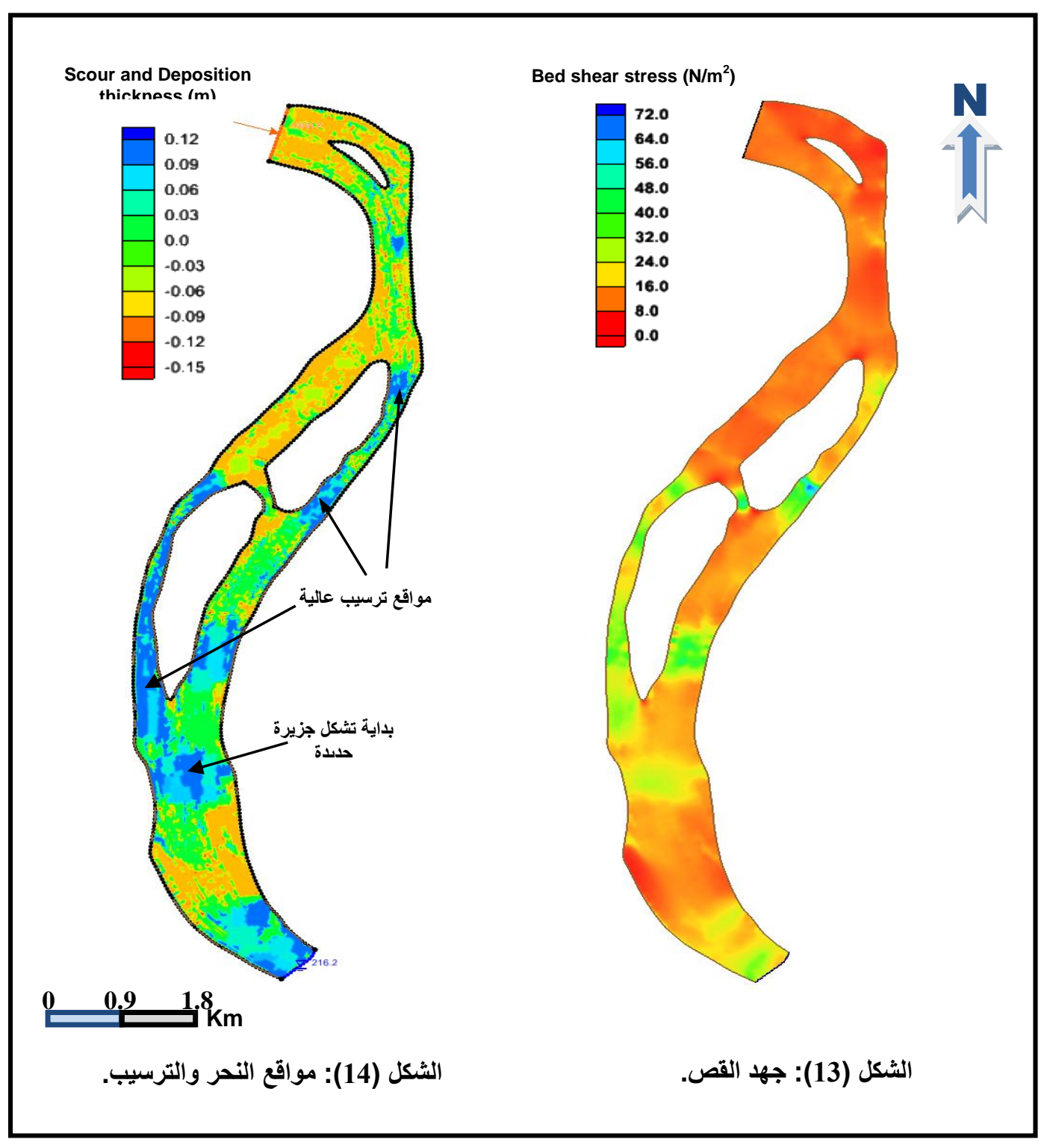

\begin{tabular}{|c|c|c|c|c|c|c|c|}
\hline \multicolumn{8}{|c|}{ الرسوبي لنهر دجلة في مدينة الموصل. } \\
\hline \multirow[b]{2}{*}{$\begin{array}{c}Q \\
\left(\mathrm{~m}^{3} / \mathrm{s}\right) \\
\end{array}$} & \multirow{2}{*}{$\frac{0.3}{K g / s}$} & \multirow{2}{*}{$\begin{array}{c}0.8 \\
\mathrm{Kg} / \mathrm{s}\end{array}$} & \multirow{2}{*}{$\frac{5}{K g / s}$} & \multirow{2}{*}{$\frac{10}{K g / s}$} & \multirow{2}{*}{$\begin{array}{c}20 \\
\mathrm{Kg} / \mathrm{s}\end{array}$} & \multicolumn{2}{|c|}{$\begin{array}{c}\text { Total sediment } \\
\text { load }\end{array}$} \\
\hline & & & & & & $\mathrm{Kg} / \mathrm{s}$ & Ton/day \\
\hline 200 & 5.6 & 7.1 & 1.75 & 0.57 & 0.2 & 15.22 & 1315 \\
\hline 400 & 15 & 18 & 4 & 1.3 & 0.5 & 38.8 & 3352 \\
\hline 600 & 25 & 30 & 6.1 & 2 & 0.78 & 63.88 & 5519 \\
\hline 800 & 53 & 51 & 11 & 4 & 1.3 & 120.3 & 10393 \\
\hline 1000 & 122 & 112 & 21 & 7 & 3 & 265 & 22896 \\
\hline
\end{tabular}


رشيد : نموذج رياضي ثنائي الأبعاد لمحاكاة نهر دجلة مقدم الجسر الثالث في مدينة الموصل
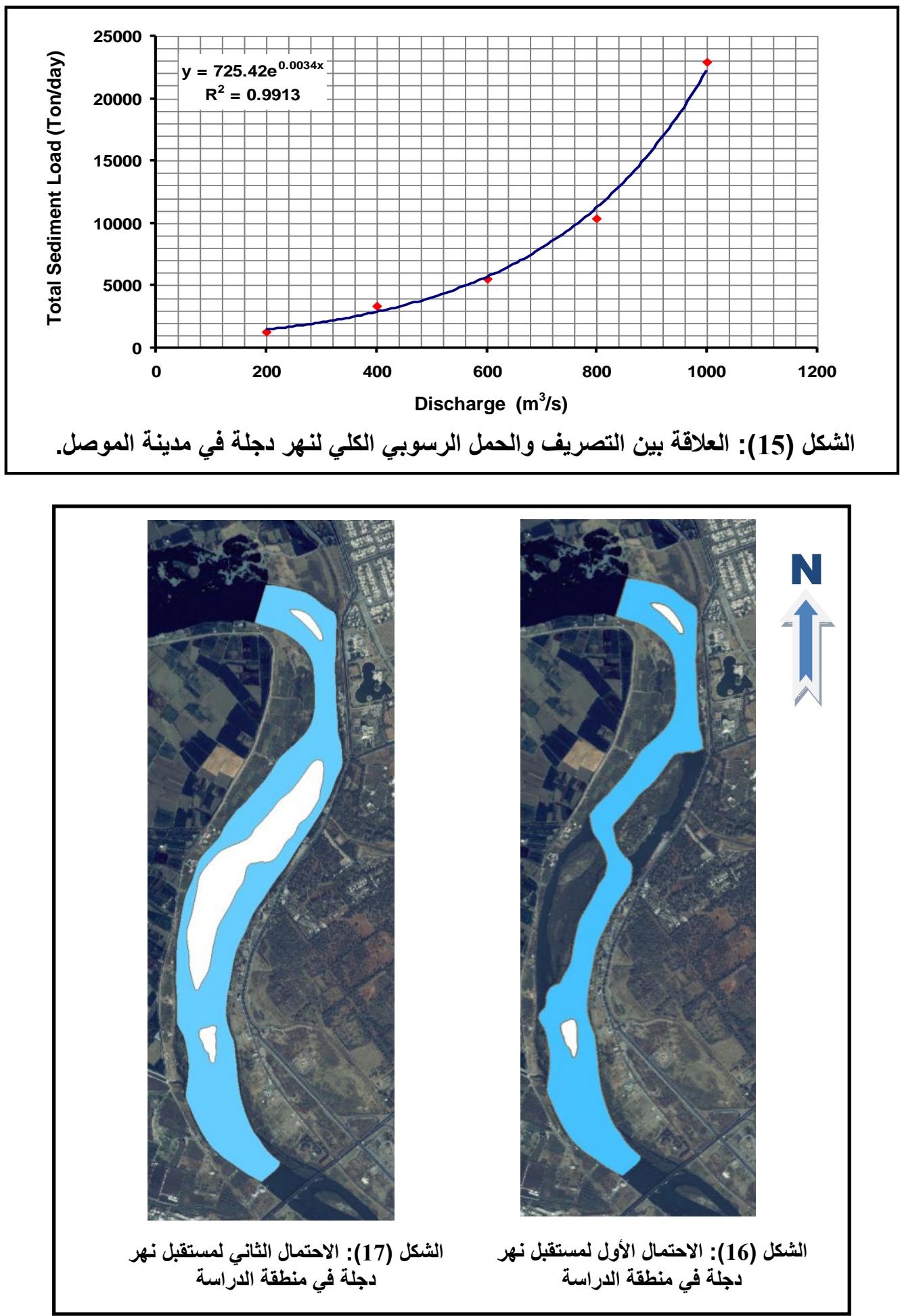

يمتاز النموذج بقدرته على تحليل أي مقطع على طول مقطع الجريان تحليلاً هيدروليكياً، وقد تم تحليل المقطع مؤخر

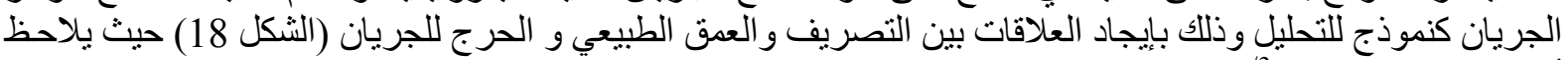

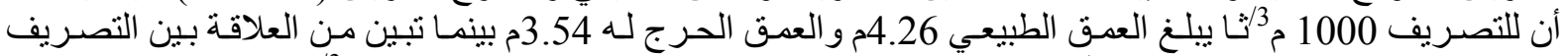

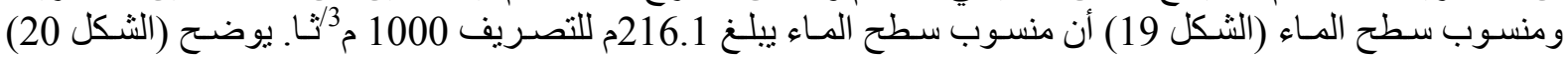

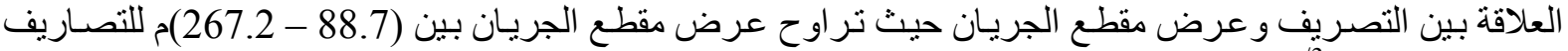

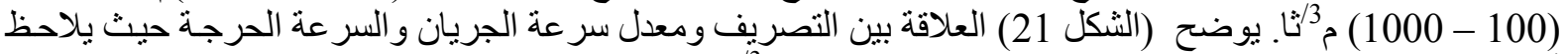

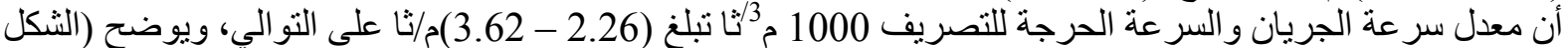
22) العلاقـة بين التصـريف و المحيط المبتـل حيث يـلـغ المحيط المبتـل (53.3 - 221.5)م للتصـاريف (100 - 1000) 
مثا. يوضح (الثكل 23) العلاقة بين التصريف ومساحة مقطع الجريان حيث تر اوحت مساحة مقطع الجريـان بين (53.3

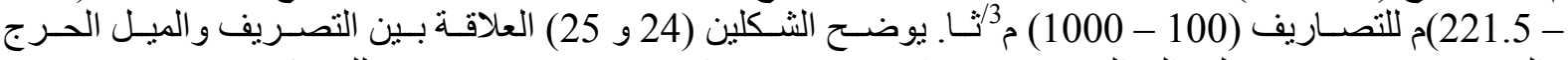
و التصريف ورقم فرود على التو الي حيث تبين ان رقم فرود تر اوح بين (0.67 - 0.73) للتصاريف (100 - 1000)

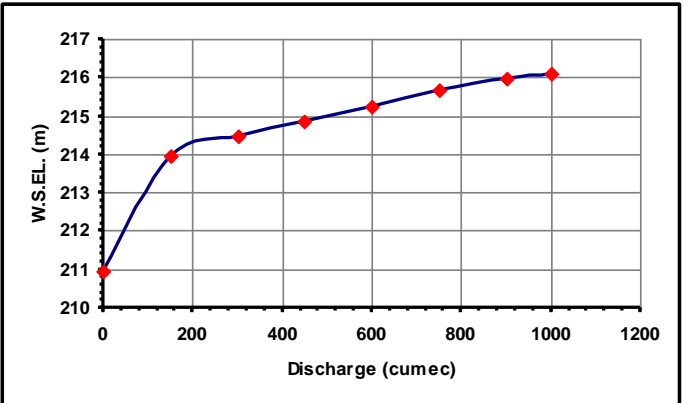

الثكل (19): العلاقة بين التصريف ومنسوب سطح الماء.

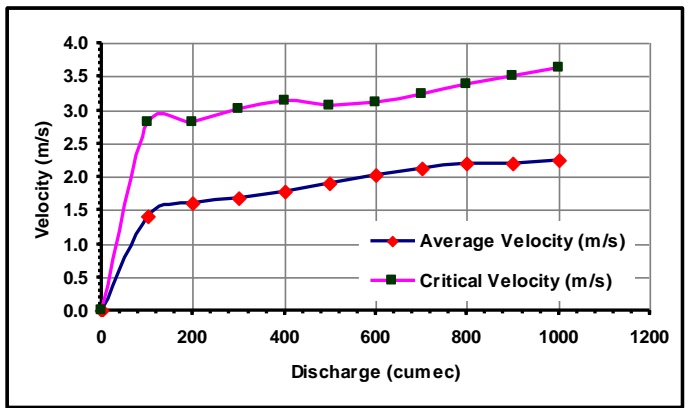

الشكل (21): العلاقة بين التصريف ومعدل سرعة الجريان والسرعة الصرجة.

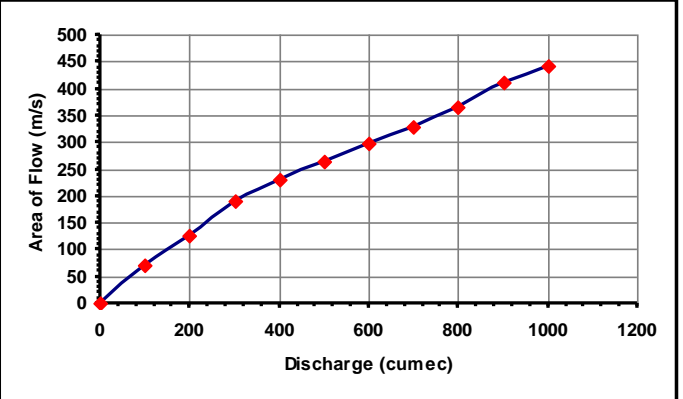

الثكل (23): العلاقة بين التصريف ومساحة مقطع الجريان.

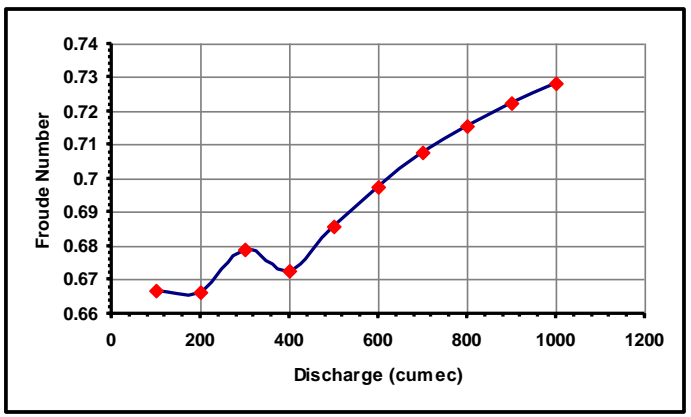

الشكل (25): العلاقة بين التصريف ورقم فرود.

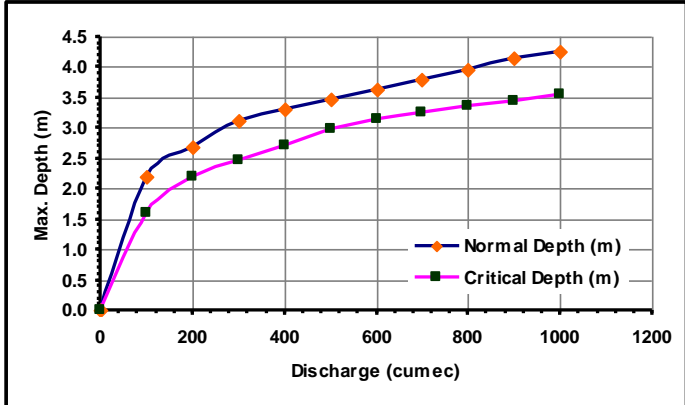

الثكل (18): العلاقة بين التصريف والعمق الطبيعي والحرج للجريان.

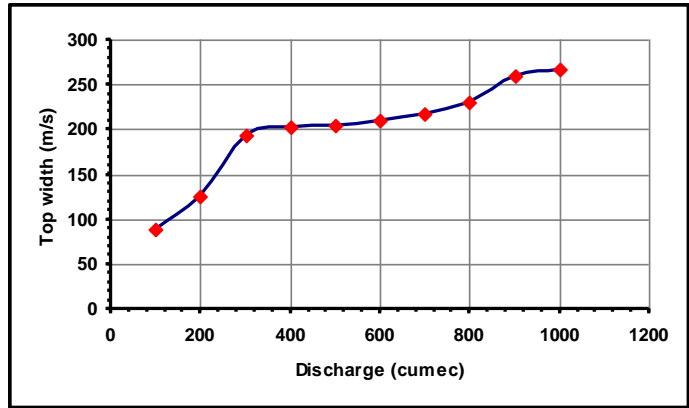

الثكل (20): العلاقة بين التصريف وعرض مقطع الجريان.

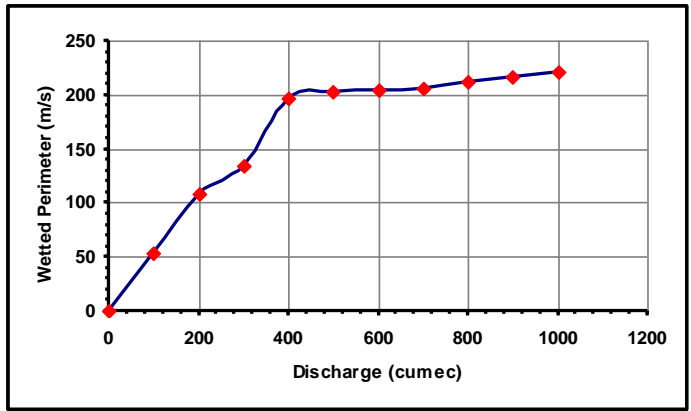

الثكل (22): العلاقة بين التصريف والمحيط المبتل.

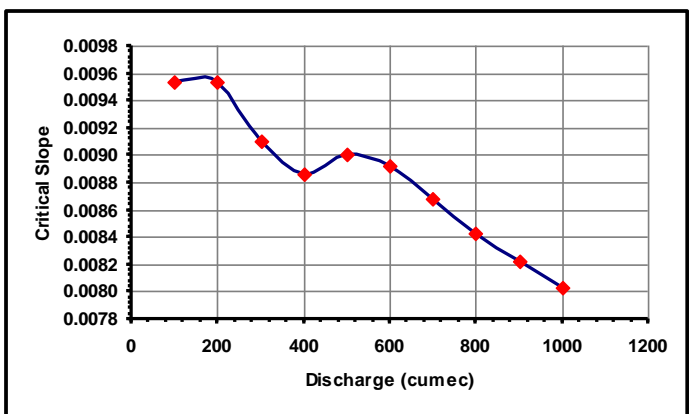

الثكل (24): العلاقة بين التصريف والميل الحرج. 


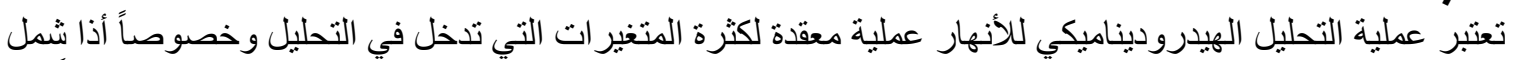

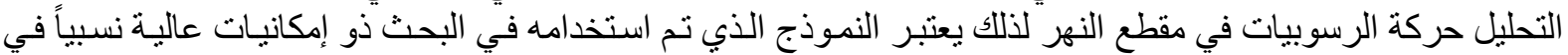

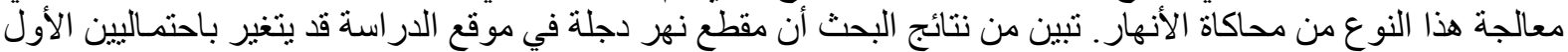

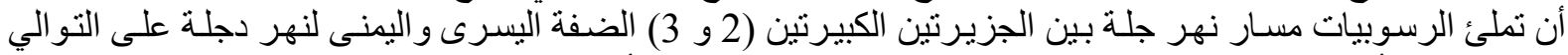

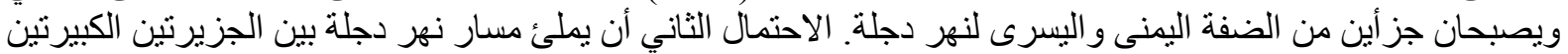

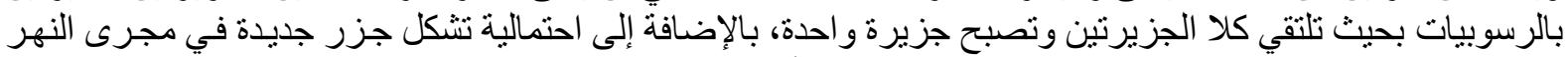

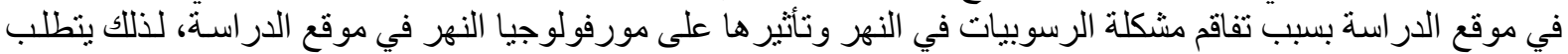

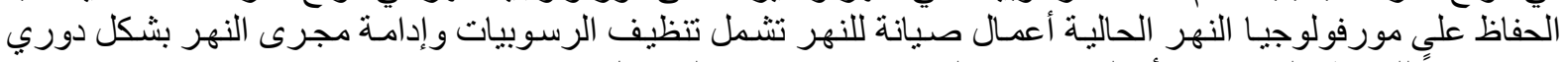

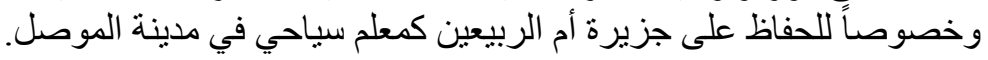

1-Garbrecht, J., Ogden, F, L, DeBarry, P, A., and Maidment, D, R., "GIS and Distributed Watershed Models. I: Data Coverages and Sources.” Journal of Hydrologic Engineering., ASCE, Vol. 6, No. 6, PP. 506-514, (2001).

2-Hossain M. Monowar \& Rahman M. Lutfor. "Sediment transport functions and their evaluation using data from large alluvial rivers of Bangladesh". IAHS Publ. no. 249, 1998.

3-Helmut M. Habersack. "Numerical sediment transport models theoretical and practical aspects" IAHS Publ. No. 249, 1998.

4- Aiwen Y. "Sediment transport at very high concentrations and movement behavior". Journal of Environmental Hydrology. Vol. 4, 1996.

5-SMS (Surface Water Modeling System) reference manual, version 10.1.Brigham Young University, Engineering Graphical Laboratory, Provo, Utah. 2009.

6- Ogden, Garbrecht, DeBarry and Johnson., “GIS and Distributed Watershed Models. II: Modules, Interfaces, and Models" Journal of Hydrologic Engineering., ASCE, Vol. 6, No. 6, PP. 515-523, (2001).

7-Federal Highway Administration. FESWMS user manual .'Two-Dimensional Depthaveraged Flow and Sediment Transport Model" .Publication No. FHWA-RD-03-053. October 2003.

8- وزارة الموارد المائية. الهيئة العامة لصيانة مشاريع الري والبزل. تقرير أعمال تهذيب نهر دجلة في مدينة الموصل.

تم اجراء البحث في كلية ألهنسة = جامعة ألموصل 